\title{
12. Fusibility of Colonies in Natural Populations of the Compound Ascidian, Botrylloides violaceus ${ }^{1)}$
}

\author{
By Hideo MuKaI*) and Hiroshi WaTanabe**) \\ (Comm. by Sajïro Makino, M. J. A., Jan. 13, 1975)
}

Colony specificity manifests itself among others as hindrance to fusion between two colonies. Bancroft (1903) was the first to take up the question of colony specificity in Botryllus, a compound ascidian. Thereafter, the genetic control of colony specificity was exhaustively investigated in the Japanese species $B$. primigenus by Oka and Watanabe $(1957,1960,1967)$ and Oka (1970). Recently, colony specificity or fusion incompatibility was found also in Botrylloides violaceus, another compound ascidian (Mukai and Watanabe, 1974), though at present no information is available on the genetic control of it. We studied the fusibility of colonies with natural populations of this species.

Material and methods. Living colonies of Botrylloides violaceus, a compound ascidian common in the vicinity of the Shimoda Marine Biological Station, were used. The colonies from either of station $\mathrm{N}$ and station $\mathrm{T}$ (see the previous paper, Mukai and Watanabe, 1975), accordingly 20 colonies in all, were collected and reared in the bay. The fusibility was tested in every combination of two colonies by bringing their cut surfaces in contact.

We thank to the staff of the Shimoda Marine Biological Station, at which the present study was done, for their help in carrying out the experiments.

Results and discussion. The results obtained are represented in Figure 1 and the fusion rates calculated from Figure 1 are listed in Table I.

Out of the 190 combinations examined, 31 (16.3\%) were fusible. The percentage of fusible combinations, however, varied with the population. That is, the population of station $\mathrm{N}$ gave a fusion rate of 8.9 per cent; while that of station $T$ gave a fusion rate of 28.9 per cent. Such a wide variation might be conceivably resulted from differences in the environmental conditions between the two stations, \footnotetext{
Japan.

*) Biological Institute, Faculty of Education, Gunma University, Gunma,

**) Shimoda Marine Biological Station, Tokyo Kyoiku University, Shizuoka, Japan.

1) Contributions from the Shimoda Marine Biological Station No. 290.
} 


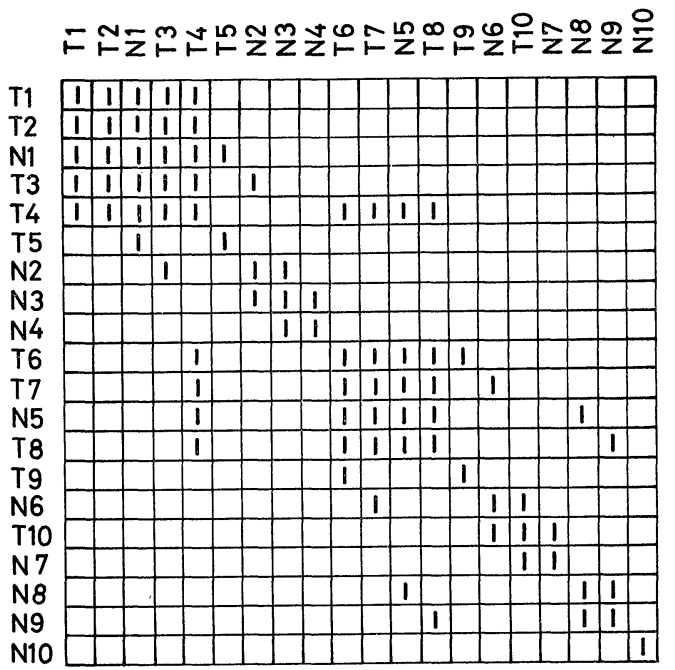

Fig. 1. Results of fusion experiments in B. violaceus. The fusible combination of colonies is represented by the square filled in with " 1 ".

Table I. Fusion rates in B. violaceus

\begin{tabular}{cccc}
\hline $\begin{array}{c}\text { Combination } \\
\text { of stations }\end{array}$ & $\begin{array}{c}\text { Number of } \\
\text { combinations } \\
\text { of colonies }\end{array}$ & $\begin{array}{c}\text { Number of } \\
\text { fusible } \\
\text { combinations }\end{array}$ & $\begin{array}{c}\text { Fusion rate } \\
(\%)\end{array}$ \\
\hline $\mathrm{N}-\mathrm{N}$ & 45 & 4 & 8.9 \\
$\mathrm{~T}-\mathrm{T}$ & 45 & 13 & 28.9 \\
$\mathrm{~N}-\mathrm{T}$ & 100 & 14 & 14.0 \\
\hline Total & 190 & 31 & 16.3 \\
\hline
\end{tabular}

though at present we cannot point out them precisely.

The genetic control of fusibility in Botryllus primigenus has been studied by Oka and Watanabe $(1957,1960,1967)$. According to them, all the results of their fusion experiments can be explained by the following assumptions: (1) Each colony in nature is heterozygotic in respect to the gene governing fusibility; (2) the gene is represented by a series of alleles like the $S$ gene governing self-incompatibility in flowering plants; and (3) colonies containing at least one gene in common are fusible with one another. The multiple alleles were designated $F^{1}, F^{2}, F^{3}$, and so on by Oka (1970). The validity of these assumptions in the natural population of $B$. primigenus was also ascertained (Mukai and Watanabe, 1975).

We applied tentatively Oka and Watanabe's rules, which were primarily presented for and derived from Botryllus primigenus, to Botrylloides also. The results thus obtained are shown in Table II. As is seen from this table, no exceptions to the rules were found. 
Table II. Genotypes of Botrylloides colonies, as determined by tentative application of Oka and Watanabe's rules presented for Botryllus primigenus

\begin{tabular}{cccc}
\hline Colony & Genotype & Colony & Genotype \\
\hline T 1 & $F^{1} F^{2}$ & T 7 & $F^{6} F^{11}$ \\
T 2 & $F^{1} F^{2}$ or $F^{1} F^{21}$ & N 5 & $F^{5} F^{12}$ \\
N 1 & $F^{1} F^{3}$ & T 8 & $F^{5} F^{13}$ \\
T 3 & $F^{1} F^{4}$ & T 9 & $F^{10} F^{14}$ \\
T 4 & $F^{1} F^{5}$ & N 6 & $F^{11} F^{15}$ \\
T 5 & $F^{3} F^{6}$ & T 10 & $F^{15} F^{16}$ \\
N 2 & $F^{4} F^{7}$ & N 7 & $F^{16} F^{17}$ \\
N 3 & $F^{7} F^{8}$ & N 8 & $F^{12} F^{18}$ \\
N 4 & $F^{8} F^{9}$ & N 9 & $F^{13} F^{18}$ \\
T 6 & $F^{5} F^{10}$ & N10 & $F^{19} F^{20}$ \\
\hline
\end{tabular}

Tentative as the application is, these results nevertheless suggest that the fusion incompatibility of Botrylloides violaceus is also controlled by a mechanism similar or related to that found in Botryllus primigenus. It seems probable that the fusion incompatibility among the colonies of Botrylloides violaceus is controlled by a series of multiple alleles at a single locus, apart from the problem whether they are necessarily heterozygotic or not. No definite conclusion is possible, however, until suitable genetic studies are carried out.

Summary. 1. Twenty colonies of Botrylloides violaceus were collected from two stations and fusion experiments were carried out in every combination of colonies.

2. Fusible combinations among colonies in one station gave a percentage of 8.9 ; those among colonies in the other station showed a high percentage of 28.9 .

3. It is suggested that the fusion incompatibility in Botrylloides violaceus is also controlled by a mechanism similar or related to that found in Botryllus primigenus, i.e., by a series of multiple alleles at a single locus.

\section{References}

Bancroft, F. W. (1903) : Proc. California Acad. Sci., Series 3, 3, 137-186.

Mukai, H., and H. Watanabe (1974) : Biol. Bull., 147, 411-421.

- (1975): Proc. Japan Acad., 51, 44-47.

Oka, H. (1970) : Colony specificity in compound ascidians. The genetic control of fusibility. Profiles of Japanese Science and Scientists (edt. by H. Yukawa).

Kodansha, Tokyo, pp. 195-206.

Oka, H., and H. Watanabe (1957) : Proc. Japan Acad., 33, 657-659.

- (1960) : Bull. Mar. Biol. Asamushi, Tôhoku Univ., 10, 153-155.

(1967): Kagaku (Tokyo), 37, 307-313. 